\section{Should Hospital Pharmacy Drug Budgets Be the Responsibility of Each Individual Department in an Institution, or Should Such Budgets Be Controlled Centrally by the Pharmacy Department?}

\section{THE "PRO" SIDE}

It is the position of our group that the responsibility for drug budgets should lie with each individual department and not solely with the pharmacy department. This approach may lead to an improvement in evidence-based practice, better patient outcomes, lower overall costs, and less wastage of medications, all without compromising the high quality of service that institutional pharmacies provide.

Putting the individual departments closest to the patients in control of drug budgets can promote patient-specific decisions based on efficacy and evidence rather than cost. ${ }^{1}$ Evidence-based practice is aimed at reducing inappropriate care and drug use, improving patient outcomes, and reducing admissions to hospital. ${ }^{2,3}$ Giving departments the authority to manage their own drug budgets tends to increase physicians' awareness of evidence-based practice. Ohlsson and Merlo ${ }^{4}$ investigated whether prescribing practices changed when physicians were made aware of the economic implications of their choices. They found that when the drug budget was decentralized, adherence to evidence-based, cost-effective practices for prescription of statins improved continuously over the 25-month duration of the study.

In addition to increasing compliance with evidence-based practice, decentralization of drug budgets allows for overall cost savings. Rising drug expenditures are outpacing inflation, which is creating an unsustainable health care system. ${ }^{5}$ Total drug spending in Canada was estimated to have reached $\$ 29.8$ billion in 2008, according to the Canadian Institute for Health Information. ${ }^{6}$ This represents an increase of about $\$ 4.5$ billion over 2006, for an estimated annual growth rate of $8.3 \%$. Physicians have very low awareness of the cost of medications. In one study, clinicians underestimated the monthly cost of $40 \%$ of the 33 most commonly used medications. ${ }^{7}$ Nonetheless, the majority of these physicians stated that they gave strong consideration to the cost of medications when patients were paying for the drugs themselves. This ignorance can have profound implications on overall drug expenditures. A Swedish survey conducted by Andersson and others ${ }^{8}$ after decentralization of drug budgets found that physicians who had experience in a decentralized system had a greater degree of cost awareness than physicians practising outside such a system. This awareness may lead to less indiscriminate dispensing of unlabelled medications on discharge from physician offices, hospitals, and emergency departments. ${ }^{9}$ Decentralization of the drug budget to individual departments and education of primary caregivers would empower physicians to become more responsible stewards of drug use.

Reducing drug wastage through education of prescribers is another potential benefit of decentralized drug budgets. Increased awareness of costs may motivate providers to decrease their drug budgets, which can in turn lead to less drug wastage. Gillerman and Browning, ${ }^{2}$ in a study of the appropriateness of disposal of unused or partially used ampoules, vials, and syringes in an anesthesia department, found that half of the dispensed quantity of every drug reviewed went unadministered. The total cost of these wasted drugs was US\$165 666 annually (2002 dollars), which represented $26 \%$ of the anesthesiology department's drug budget. Only $27 \%$ of the physicians were able to identify the per-milligram cost of the most expensive drugs, and only 29\% accurately estimated the dollar amount represented by wasted drugs. Gillerman and Browning concluded that "the education of providers about use, waste and cost is essential as perceptions of cost or total lost dollars for a given drug may be different from reality."

If drug budgets are allocated to individual departments, hospital pharmacy departments will continue to play a vital role in various drug-related services, including procurement, storage, dispensing, and clinical and support services. With a decentralized system, it is still feasible to have a single formulary and a unified pharmacy and therapeutics committee. Pharmacists can still be involved in the development and maintenance of a costeffective, evidence-based formulary. The American Society of Health-System Pharmacists has stated that, in developing an effective formulary system, pharmacists are essential members of the multidisciplinary committee, because they can provide suggestions for balancing pharmacoeconomic concerns with the evidence for a particular medication. ${ }^{10}$ Feely and others ${ }^{11}$ found that interventions such as feedback on prescribing habits, comparisons with peers, and cost information about drugs helped to reduce inappropriate prescribing and increase compliance with the formulary. The pharmacy department can continue to oversee the logistic aspects of drug procurement and inventory control to ensure that sufficient supplies of formulary medications are maintained, thus deterring inappropriate prescribing caused by lack of stock. ${ }^{10}$ The pharmacy inventory and order entry system will continue to collect data that can be used to review prescribing trends. Such data would be provided to department heads to assist them in managing their individual budgets.

Incorporating drugs into an individual departmental budget promotes prescription stewardship by physicians, removing the perception of pharmacists as the "drug budget police". Enforcement of prescribing according to a formulary would instead be the responsibility of each department head. Eliminating this "policing" role might allow for better interdisciplinary relation- 
ships and improved collaborative care. Placing the onus for the medication budget on individual departments might lead to improvements in evidence-based practice and patients' outcomes, as well as reductions in the costs and wastage of medications.

References

1. Nujiten MJC, Kosa J, Engelfriet P. Modeling the cost-effectiveness and budgetary impact for subpopulations. Eur J Health Econ 2003;4(2):70-78.

2. Gillerman RG, Browning RA. Drug use inefficiency: a hidden source of wasted health care dollars. Anesth Analg 2000;91(4):921-4.

3. Fonarow GC, Yancy CW, Albert NM, Curtis AB, Stough WG, Gheorghiade $\mathrm{M}$, et al. Improving the use of evidence-based heart failure therapies in the outpatient setting: the IMPROVE HF performance improvement registry. Am Heart J 2007;154(1):12-38.

4. Ohlsson H, Merlo J. Understanding the effects of a decentralized budget on physicians' compliance with guidelines for statin prescription-a multilevel methodological approach. BMC Health Serv Res 2007;7:68.

5. Grocott R. Applying programme budgeting marginal analysis in the health sector: 12 years of experience. Expert Rev Pharmacoecon Outcomes Res 2009;9(2):181-187

6. Drug expenditure in Canada 1985 to 2008. Ottawa (ON): Canadian Institute of Health Information; 2009 [cited 2009 Dec 29]. Available from: http://secure.cihi.ca/cihiweb/products/drug_expenditure_1985_ 2008_e.pdf

7. Reichert S, Simon T, Halm EA Physicians' attitudes about prescribing and knowledge of the costs of common medications. Arch Intern Med 2001;161(10):1352-1353.

8. Andersson K, Carlsten A, Hedenrud T. Prescribing behaviour after the introduction of decentralized drug budgets: Is there an association with employer and type of care facility? Scand J Prim Health Care 2009; 27(2):117-122.

9. Part 1: Community pharmacy standards of practice. In: HPA [Health Professions Act] bylaws Schedule F. Vancouver (BC): British Columbia College of Pharmacists; 2009 [cited 2010 Jun 27]. Available from: www.bcpharmacists.org/library/D-Legislation_Standards/D-2_ Provincial_Legislation/5078-HPA_Bylaws_Community.pdf

10. Nissen L. Current status of pharmacist influences on prescribing of medicines. Am J Health Syst Pharm 2009;66 Suppl 3:S29-S34.

11. Feely J, Chan R, Cocoman L, Mulpeter K, O'Connor P. Hospital formularies: need for continuous intervention. BMJ 1990;300(6716):28-30.

Kendra Bernard, BSC(Pharm), ACPR

Emily Black, BSC(Pharm), ACPR

Shahileen Remtulla, BSC, BSC(Pharm), ACPR

Erin Schwenger, BSc(Pharm)

PharmD Students

Dawn Dalen, BSP, ACPR, PharmD

Clinical Assistant Professor

Faculty of Pharmaceutical Sciences

University of British Columbia

Vancouver, British Columbia

Dawn Dalen is also the Regional Pharmacy Practice Coordinator and Clinical Pharmacist Specialist-Emergency Medicine, Interior Health Authority, Kelowna, British Columbia.

\section{THE "CON" SIDE}

The centralization of pharmacy drug budgets is supported by the 1993 medication safety guidelines of the American Society of Hospital Pharmacists (now the American Society of Health-System Pharmacists), which recommended that "the pharmacy department must be responsible for the procurement, distribution, and control of all drugs used within the organiza- tion". 'This approach strategically positions pharmacists to better function as medication experts, leading the development, evaluation, and maintenance of hospital formularies, preprinted orders, and practice guidelines, and the initiation of cost-management strategies. The pharmacy department offers expertise in negotiations with pharmaceutical companies, therapeutic recommendations, evidence-based clinical information, and collaborative practice. ${ }^{2}$ In contrast, decentralization of drug budgets increases overall costs by fostering fragmentation and inefficiencies within the hospital's medication management process.

The process of developing a drug budget is complex and time-intensive. In decentralized systems, each department must perform this process separately, whereas the process is more efficient and comprehensive in a centralized system. ${ }^{3}$ Decisions related to drug budgets are associated with economic demands for the time of pharmacy personnel, including time required for retrieving and delivering medications, compounding IV admixtures, and managing drug packaging materials and technology. Decentralized decision-making results in an uneven distribution of goods and services to different wards, a decrease in standardization and efficiency, and increases in the cost of service provision.

In a decentralized system, stock must be segregated into several caches according to who "owns" the medications; this can lead to logistic challenges in storage and tracking. Assigning drug costs to each department as patients are transferred from one service to another is time-consuming and requires an information system to track and provide timely statistics on usage, costs, and supplies. In contrast, a centralized system allows for procurement and stock-control processes that minimize acquisition costs and wastage. These processes include monitoring of expiry dates, recycling of dispensed but unused medication, and strategic allocation of high-demand, back-ordered, or expensive drugs to areas of urgent need.

Departmental control of drug budgets is not conducive to the maintenance of a unified formulary, as decentralized entities focus on individual performance rather than that of the entire organization. In a decentralized system, each department has different formulary drug preferences and will argue for larger budgets based on its own baseline drug costs. In a centralized system, the pharmacy can effectively influence such costs by developing policies for therapeutic substitutions, automatic stop orders, and restricted drug use, tailoring them to departmental resources and hospital needs.

Having a less concise formulary in a decentralized system generates a greater variety of line items and ties up more resources in inventory. This increases opportunities for wastage through expiry of medications and requires more physical storage space. ${ }^{2}$ Decentralized processes also compromise institutions' leverage on bulk buying contracts; in contrast, centralized tendering in a competitive bidding process yields the best price for the organization. ${ }^{3}$

Increased drug stock in a decentralized system augments the risk of medication errors through the availability of multiple strengths or types of medications. ${ }^{5}$ The Institute of Medicine has noted that preventing mistakes requires designing the health care system at every level to make it safer, and advocates that building 
safety into processes of care is an effective way to reduce errors. ${ }^{6}$

A centralized process supports a comprehensive approach to utilizing pharmacists' expertise in medication safety, but the variability and autonomy of prescribers in a decentralized system presents several concerns. For example, the average cost per prescription within the North Carolina Medicaid program increased because of a shift in prescribing patterns toward more expensive drugs and a trend toward more rapid adoption of expensive new drugs by physicians. ${ }^{7}$ Failure to apply the principles of evidence-based prescribing can result in ad hoc practices, suboptimal patient outcomes, adverse drug reactions, and poor use of resources. ${ }^{8}$ Numerous studies have shown that physicians estimate drug costs poorly, ${ }^{9}$ whereas centralized pharmacy departments can systematically collect and analyze drug utilization patterns (drug utilization reviews), using these data to reduce drug expenses. ${ }^{8}$ Hospital-wide guidelines can be implemented with restrictive measures (such as therapeutic substitution) to garner appropriate and cost-effective prescribing, while maintaining quality of care.

Decentralization may precipitate conflicts of interest. For example, Chren and Landefeld ${ }^{10}$ demonstrated that physicians who interacted with specific drug companies were 9 to 12 times more likely to request that the company's drug be added to the formulary. The centralized model, wherein the pharmacy manager acts as the intermediary between medical and economic interests, puts the prescriber at arm's length from the selection of brands, contracting, and purchasing. ${ }^{11}$

Centralizing the drug budget exploits the wealth of medication expertise offered by the pharmacy department. Pharmacists are the optimal health professionals to serve as unbiased, practical, evidence-based mediators, because they are able to select the most appropriate and most effective drug therapies, while being cognizant of drug costs. Therefore, hospitals' drug budgets should be the responsibility of the pharmacy department, and not the responsibility of each individual department.

\footnotetext{
References

1. ASHP guidelines on preventing medication errors in hospitals. $A m J$ Hosp Pharm 1993;50(2):305-14.

2. Stokoe R, Samways D. Budget management. In: Stephens M, editor. Hospital pharmacy. London (UK): Pharmaceutical Press; 2006. p. 17-28.

3. Rubino MS, Hoffman JM, Koesterer LJ, Swendrzynski RG. Systematic approach to medication-cost-management measures. In: Hawkins B, editor. Best practices for hospital and health-system pharmacy. Bethesda (MD): American Society of Health-System Pharmacists; 2008. p. 295-301.

4. Abramowitz PW. Controlling financial variables - changing prescribing patterns. Am J Hosp Pharm 1984;41(3):503-515.
}

5. Paparella $S$. Drug storage in the emergency department: when accessibility $\neq$ safety. J Emerg Nurs 2008;34(4):355-356.

6. Executive summary. In: Kohn LT, Corrigan JM, Donaldson MS, editors. To err is human: building a safer health system. Washington (DC): Institute of Medicine; 2000. p. 4.

7. Jancin B. Soaring Medicaid drug costs highlight prescribing trends. Clin Psychiatry News 2006 Jun [cited 2009 Oct 1];29(6):63. Available from: http://findarticles.com/p/articles/mi_hb4345/is_6_29/ai_n28851144/

8. MacIntyre CR, Sindhusake D, Rubin G. Modelling strategies for reducing pharmaceutical costs in hospital. Int J Qual Health Care 2001;13(1):63-69.

9. Shrank WH, Asch SM, Joseph GJ, Young HN, Ettner SL, Kholodenko Y, et al. Physicians' perceived knowledge of and responsibility for managing patients' out-of-pocket costs for prescription drugs. Ann Pharmacother 2006;40(9):1534-1540.

10. Chren MM, Landefeld CS. Physicians' behavior and their interactions with drug companies. A controlled study of physicians who requested additions to a hospital drug formulary. JAMA 1994;271(9):684-689.

11. Roberts P, Sharott P. Budget management. In: Stephens M, editor. Hospital pharmacy. London (UK): Pharmaceutical Press; 2006. p. 238-239.

Katherine Seto, BSc(Pharm), ACPR, RPh

Sarah Stabler, BSC(Pharm), ACPR, RPh

Victoria Su, BSC(Pharm), ACPR, RPh

Flora Young, BSc(Pharm), ACPR, RPh

PharmD Students

Sam Louie, BSc(Pharm)

Adjunct Professor

Faculty of Pharmaceutical Sciences

University of British Columbia

Vancouver, British Columbia
The Pro and Con articles for this issue's "Point Counterpoint" column were developed from a debate held in fall 2009 as part of the course Advanced Pharmacy Administration - Topics in Contemporary Practice, in the Doctor of Pharmacy program at the University of British Columbia. 